\title{
Insurance Decisions for Low-Probability Losses
}

\author{
Susan K. Laury* and Melayne Morgan McInnes ${ }^{\dagger}$ and J. Todd Swarthout ${ }^{\ddagger}$
}

October 31, 2008

\begin{abstract}
It is widely accepted that individuals tend to underinsure against low-probability, high-loss events relative to high-probability, low-loss events. This conventional wisdom is based largely on field studies, as there is very little experimental evidence. We reexamine this issue with an experiment that accounts for possible confounds in prior insurance experiments. Our results are counter to the prior experimental evidence, as we observe subjects buying more insurance for lower-probability events than for higher-probability events, given a constant expected loss and load factor. Insofar as underinsurance for catastrophic risk is observed in the field, our results suggest that this can be attributed to factors other than only the relative probability of the loss events.
\end{abstract}

Key words: low-probability hazards, insurance, risk, experiments

JEL Classification: C91 D80

Acknowledgements: We thank seminar participants at Fordham University, Medical University of South Carolina, University of Michican, and University of North Carolina at Charlotte. Funding was provided by the National Science Foundation (SBR-9753125 and SBR-0094800).

\footnotetext{
${ }^{*}$ Georgia State University, prcskl@langage.gsu.edu

${ }^{\dagger}$ University of South Carolina, mcinnes@moore.sc.edu

${ }^{\ddagger}$ Georgia State University, swarthout@gsu.edu
} 


\section{Introduction}

Do people treat very low probability outcomes as if they are ignorable? In formulating cumulative prospect theory, Tversky \& Kahneman (1992) note that the probability weighting function is not well-behaved near zero. While probability weighting allows for overweighting of small probabilities, very small probabilities appear to be either "rounded down" to zero or greatly overweighted. Studies of the demand for insurance, both in the laboratory and in the field, suggest a pattern consistent with ignoring very low probability events. Individuals who demand insurance for small losses do not demand insurance for larger, less frequent losses. One explanation for this behavior is that people only pay attention to risks when the likelihood of occurrence rises above some probability threshold (Kunreuther \& Pauly, 2005, 2004; Slovic et al., 1977). This threshold may be optimally chosen by a decisionmaker who faces information search costs-including psychic costs - or may be better described as "worry" or "concern" and depend on situational factors such as fear or other emotions.

In order to study this anomalous pattern of behavior in controlled laboratory conditions, we first need to identify conditions which reliably reproduce the behavior. This was surprisingly challenging and the experiments reported here show that insurance behavior in the laboratory is very sensitive to how the losses are framed and the type of incentives used. When insurance decisions are presented in abstract terms with no money on the line, subjects were indeed less likely to insure against smaller probability losses. However when we frame decisions in a less abstract context and express losses in dollar terms, we observe that insurance behavior is reversed, even when stakes are hypothetical. That is, we find that individuals are more likely to purchase insurance for the higher-consequence, lower-probability events. Perhaps most striking, this pattern is strongest when incentives are real and subjects face the prospect of actually losing money. Our results clearly demonstrate that if there is an attention threshold for insuring against catastrophic events, then factors other than loss probability must be considered.

\subsection{Motivation}

After every major flood or hurricane, the question of why homeowners and businesses do not adequately insure against catastrophic risk is brought to national attention. While high underwriting 
costs and limited supplies of insurance for extreme events may provide a partial explanation, low take-up rates of federally subsidized flood insurance suggest that this is not the entire explanation. It is a widely-reported empirical puzzle that insurance rates for low-probability, high-consequence losses are low relative to higher-probability, low-consequence losses.

While there is little consensus on the reason for this, one explanation has gained prominence in recent years. There is widespread evidence that individuals have a difficult time processing probabilities, and some researchers speculate that people frequently fail to distinguish between low-probability and zero-probability events (see, for example, Kunreuther et al., 2001). As an illustration, Kunreuther \& Pauly (2004) quote a homeowner about his decision of whether to purchase earthquake insurance. The homeowner concluded "The more I look at this, the more it seems my chances of having a covered loss are about zero."

Kunreuther \& Pauly suggest a model of bounded rationality for the individual's insurance purchasing decision. At its heart is the idea that consumers face uncertainty about the probability of a loss and insurance load, and therefore "events that have a low expected value also have a low expected return from searching for information on the benefits of insurance relative to its cost." (Kunreuther \& Pauly, 2004, p. 18) They suggest several remedies to increase the rate of insurance for these low-probability, high-loss events. One such suggestion is offering bundled policies that insure against multiple causes of loss. Although the probability of each cause may be very low, when several loss-causes are bundled (e.g., loss from fire, theft, flood, and earthquake) the combined probability may rise above the consumer's "attention threshold" and therefore make the consumer more likely to insure. If consumers fail to insure against low-probability losses because they do not distinguish between a low probability and a zero probability, then offering bundled policies should increase the rate of purchase.

Controlled laboratory experiments are an ideal testbed for policy solutions such as this because one can control for possibly confounding factors in the laboratory in a way that is not possible in the field. For example, the probability of an individual loss, insurance load and information can be held constant between treatments in which individual policies and bundled policies are sold. For this reason, we conducted a pilot experiment designed to test whether offering bundled policies for several losses would increase the rate of purchase relative to a treatment in which subjects had to purchase policies separately for each loss. The results of the pilot presented us with a puzzle: 
there was no room for bundling to increase the rate of purchase because subjects in this experiment purchased the individual policies in almost all cases, even when the probability of an individual loss was quite low. Before trying to study the underlying mechanisms of this anomaly or policy solutions, we first needed to be able to reproduce the anomaly in the laboratory.

Our pilot results led us to dig more deeply into the experimental literature that reports a positive relationship between the probability of a loss and the rate of insurance purchase (holding constant the load and expected value of a loss). An extensive review of the literature revealed that the primary sources for this result were three papers: Slovic et al. (1977), McClelland et al. (1993), and Ganderton et al. (2000).

The study that most closely resembles naturally-occurring insurance markets is Ganderton et al. (2000). Subjects earned income each period and, in repeated decision-making rounds, were asked whether or not they wish to purchase insurance at a stated price. Each subject made insurance purchase decisions under a wide range of premiums, loss probabilities and loss amounts. Ganderton et al. found that the probability of purchasing insurance increased with the probability of a loss, but their experiment has two features that limit the generalizability of their result. First, large losses were nearly always truncated by a low-cost bankruptcy condition such that the ratio of the nominal loss to the potential for realized losses varied over time and across subjects. Second, the probability and size of loss were varied independently in their experiments, therefore the expected value of a loss was not held constant.

McClelland et al. (1993) conducted an earlier experimental study of insurance-purchase decisions. In this study, real payments were used, but the mechanism used by subjects to purchase insurance does not closely reflect the mechanism used in naturally-occurring markets. In this experiment, groups of eight subjects participated in a Vickrey fifth-price auction, and thus only half of the subjects were able to buy insurance during a given round. They found a bimodal pattern of bidding; when the probability of a loss was low, bids were most common at zero and twice expected value. Their finding that a non-trivial subset of subjects are unwilling to pay any positive amount to insure against a low probability $(\mathrm{p}=0.01)$ loss persisted even when the stakes were high and subjects were experienced. These results were interpreted as generally supportive of the artifact that less insurance purchase occurs at lower probabilities than at higher probabilities. However, behavioral patterns for bidding in an auction may not reflect decision-making patterns in naturally- 
occurring insurance markets. In fact, Harbaugh et al. (2005) offer evidence that individuals exhibit sharply different behavior when they are offered a choice between gambles over losses and when they are asked to submit a price they are willing to pay for the same gamble. Naturally-occurring insurance markets more closely resemble a choice task (consumers choose between a certain lossthe price of insurance - and a probability of a loss if no insurance is purchased) than a pricing task (submitting a bid to buy insurance in an auction). Therefore one should be cautious when interpreting results from an auction to make inferences about purchasing decisions in insurance markets.

The most widely-cited laboratory study of insurance purchasing decisions was conducted by Slovic et al. (1977). This was a carefully-crafted experiment in which subjects filled out a questionnaire that elicited their willingness to purchase actuarially fair insurance in up to eight different situations. The probability of a loss was presented in terms of draws of orange and white balls from an urn, and a loss occurred only when an orange ball was drawn. The probability and size of the loss were systematically varied across questions, holding constant the expected value of the loss and the (actuarially fair) premium. For example, in one scenario there were 9,999 white balls and 1 orange ball, and the loss if an orange ball was drawn was 10,000. In another scenario, subjects were told that there were 9,000 white balls and 1,000 orange balls, and the loss if an orange ball was drawn was 10. In each of the scenarios subjects were asked whether they would purchase insurance at a price of one.

They found that the percentage of subjects purchasing insurance was relatively low (less than 10 percent) when the probability of a loss was very low (and therefore the loss amount was high), and systematically increased as the probability of a loss increased. While this study was carefully constructed, two features of the experiment led us to question their results. In almost all of their treatments, they used hypothetical incentives; subjects were paid for their participation, but not based upon the answers to the questionnaire. Also, the questions were not framed in terms of monetary payments and losses. All losses and insurance prices were reported in terms of "points" (e.g., the insurance premium was 1 point in all questions).

Given our concerns about these experiments, we decided to undertake a systematic study of the effect that the probability of a loss has on insurance purchase decisions. More specifically, we study whether subjects in the laboratory are more or less likely to purchase insurance as the probability 
of loss increases, holding constant the expected value of the loss and the insurance load.

We begin by replicating the Slovic et al. experiment, which we describe in Section 2 below. Next, we implement a laboratory insurance experiment that more closely resembles naturally-occurring insurance markets. As we describe in Section 3, subjects earn their initial endowment $(\$ 60)$ and then make a series of insurance purchase decisions. In some treatments subjects face the loss of their entire earned endowment.

\section{Slovic et al. Replication Experiment}

In our replication of the Slovic et al. experiment, subjects were given a questionnaire, and asked whether they would purchase insurance in a number of different hypothetical situations (six or eight, depending on the treatment). Although complete instructions were not included in the original paper, the authors quoted extensively from their instructions. To the extent possible, we used their wording in our instructions (see Appendix A).

Following this design, subjects in our experiment were told that they would not play out any of the gambles that were presented in the questionnaire. The instructions stated:

Each game consists of drawing one ball from each set of baskets. Each contains a different mixture of orange and white balls. If I were to draw a white ball, no loss would occur. If I were to draw an orange ball, this would result a loss, unless you had purchased insurance. (Remember, we will not actually play any of these gambles, but I want you to think about each as if you were really going to play each one.)

In each situation, the subject was told the number of orange and white balls, the loss if an orange ball were drawn, and the price of purchasing insurance. The subject was then asked to indicate on the form whether or not she would purchase insurance in this situation.

We selected parameters to replicate one of the treatments reported by Slovic et al. In each situation, the number of orange and white balls was varied so that the probability of a loss ranged from .0001 to .50; in every situation, the expected value of a loss was 1 point (so the losses ranged from 10,000 points to 2 points), and insurance was always actuarially fair (the price of insurance was held constant at 1 point in each situation). No monetary units were used: all losses and insurance prices were expressed in points. For example, in one situation, the subject was told the basket contained 999 white balls and 1 orange ball; if an orange ball was drawn, the individual 
would lose 1000 points.

A total of 34 subjects participated in this experiment, with each session lasting less than one hour.

\section{$2.1 \quad$ Experiment 1 Results}

Table 1 presents the percentage of subjects who buy insurance in each of the eight gambles. ${ }^{1}$ While Slovic et al. do not provide a comparable table, we have obtained estimates from a figure in their paper and show them for comparison with our results. Subjects in our experiment are more likely to purchase insurance at low probabilities than those in the original study. Over twenty-five percent of our subjects purchased insurance when the probability of a loss was .0001 or .001, compared with approximately sixteen percent and twelve percent, respectively, in Slovic et al. However, as shown by Figure 1, the main feature of their data is replicated in our experiment: the percentage of subjects purchasing insurance increases as the probability of a loss increases. In our session, twenty-six percent of subjects say they would buy when the probability of a loss is .0001, compared with forty-seven percent of subjects who say they would buy when the probability of a loss is 0.01 , and sixty-eight percent when the probability of loss is $0.5 .^{2}$

Given that we are able to replicate their key finding, we next turn to an exploration of the robustness of this phenomenon. We describe a new experiment that tests the pattern of insurance buying behavior when the decision problem is framed in terms of monetary losses and monetary costs of insurance, and when the losses faced by subjects are real and large.

\section{New Experiment on the Effect of Loss Probability on Insurance Purchase}

Moving away from the hypothetical payment and abstract context of the Slovic et al. replication, we were faced with several challenges in implementing a credible catastrophic loss in the

\footnotetext{
${ }^{1}$ The level of insurance purchase reported by Slovic et al. varied depending on the treatment, but the overall pattern of behavior (higher rates of insurance purchase as the probability of a loss increased) was consistent across treatments.

${ }^{2}$ The p-value for McNemar's one-tailed test conditional on the sum of discordant pairs is $\mathrm{p}=.0096$ comparing the purchase rates for loss probabilities of .001 and .01 , and $\mathrm{p}=.0461$ comparing purchase rates for loss probabilities of .01 and .5 . We provide a more detailed description of McNemar's test below.
} 
lab. We first describe how we address these design considerations and then describe our treatments. After this we describe the full experimental design, and then present the results from this experiment.

\subsection{Implementing Catastrophic Losses in the Lab}

There are two features of the naturally-occurring problem that were important to replicate in the lab: the low probability of a loss, and the high-consequence amount of the loss. For example, the probability of catastrophic damage from a flood, fire, or earthquake may be very low; but in the event a loss occurs, the amount of the loss (including the destruction of one's home and the loss of belongings) will likely be very high. In the laboratory, we are challenged to implement losses that are viewed by the subjects as both consequential and "true losses" (and not just lesser gains). The size of the stakes is also of interest because of recent findings showing that individuals appear much more risk averse for high stakes gambles than low stakes or hypothetical stakes (Camerer \& Hogarth, 1999; Holt \& Laury, 2002, 2005; Harrison et al., 2005).

In order to minimize a found-money effect and therefore to make the loss more real to subjects, they earned their endowments before they faced the insurance-purchase decisions. Subjects earned up to sixty dollars in a separate earnings task prior to insurance decisions (described below). To ensure that the potential loss was viewed as substantial, subjects faced the potential loss of all of this earned income in some situations. In addition, potential losses were never larger than a subject's available income in order to avoid confounding the size of losses with bankruptcy considerations.

The only part of a subject's experiment earnings that was not at risk was a $\$ 10$ participation payment. At the start of the experiment, subjects were paid this participation payment and signed a receipt for it. Our goal was for subjects to consider their participation payment separately from their experiment earnings so that any loss of earned income would be considered a real loss. To this end, subjects were given the following written statement after signing a receipt for their participation payment:

In this experiment, you will participate in more than one decision-making task. You will have the opportunity to earn money in the first task. The second task has the possibility of a negative outcome; if a negative outcome occurs, any money lost will be taken out of your earnings from the first task.

You have already received $\$ 10$ for your participation in today's experiment. This money 
is yours to keep, and you should put it away. You will NOT be asked to risk your $\$ 10$ participation fee in today's experiment. Any other money that you earn in today's experiment will depend on your choices, and also on chance. However, you will not leave the experiment with any additional money (other than the $\$ 10$ participation fee that you have already received) unless you complete the entire experiment today.

If you wish to withdraw at this time or at any time during the experiment, you may do so and keep your $\$ 10$ participation fee. Please initial this form to indicate that you understand this.

All subjects initialed this form and continued their participation in the experiment, and, therefore, we do not have to be concerned about any sample selection issues.

\subsection{Treatments}

The primary factor of interest is the probability of experiencing a loss. We chose to use two different levels: 1 percent and 10 percent. The choice of probabilities was based on practical considerations, as well as guidance from Slovic et al. and our replication. In both of these prior experiments, there was a substantial change in the proportion of subjects buying as the probability of a loss increased from 1 percent to 10 percent (from 47 percent to 62 percent buying in our replication, and from about 25 percent to 64 percent reported in Slovic et al.). Therefore, we believed that these two loss-probabilities would be sufficient to test the effect of the probability of a loss on the rate of insurance purchase.

In addition, these probabilities allowed us to determine the outcome of the gamble publicly and in a manageable way. When the probability of a loss was 1 percent, we placed 1 orange and 99 white ping-pong balls into a bingo cage. If we had focused on smaller probabilities, this would have required us to use many more ping-pong balls and therefore we could not have reasonably used a bingo cage to determine the outcome of the gamble. Instead, these small probabilities would have required us to use a less transparent manual randomization device or a computerized randomization device. We preferred the transparency of a manual draw that could be observed by all subjects, and so we limited our attention to this range of probabilities. In addition, in this range of loss probabilities, we could present subjects with the potential loss of the entire endowment without a prohibitively high cash endowment at the beginning of the experiment. For example, with a loss-probability of .001 and expected value of a loss of just $\$ 0.15$, the loss amount would be $\$ 150$. If the subject were to really face such a loss in the laboratory, the initial endowment would have 
to be at least $\$ 150$.

Slovic et al. restricted their attention to actuarially fair insurance. However the insurance literature addresses the issue of under-insurance with respect to subsidized insurance and insurance that is priced above the expected value of a loss. Based on results from field data, the ratio of the premium to expected benefit (referred to as the "load" throughout) was set at three levels: 0.80 , 1.0, and 4.0. When the load is set at 0.8 , the price of insurance is 80 percent of the expected value of the loss. We included subsidized insurance because field data indicate that individuals fail to purchase insurance against low-probability events, even when it is heavily subsidized (Anderson, 1974). When the load is 1.0, the insurance is actuarially fair, and we are able to compare our results to our replication experiment in these decisions. When the load is 4.0, the price of insurance is four times the expected value of the loss. While a load of 4.0 seems high, analyses of non-group health insurance markets (Pauly et al., 1999) and catastrophic insurance markets (Harrington \& Niehaus, 2003) suggest loads can be as high as 2.5 to 5. By varying the load we can test the robustness of our results to the size of the load. In addition, by introducing a high load, we may move some of the sample closer to the margin between buying and not buying insurance and, thus, may have a better chance of observing a treatment effect as we change the loss probabilities.

In choosing the expected value of the loss, we found little guidance in the literature, but experience with our subject pool suggests that losses of $\$ 30$ to $\$ 60$ are viewed as non-trivial. Because the maximum possible loss in the experiment could be no larger than the subject's (earned) endowment (which was $\$ 60$ in every case but one), the expected value of the loss was set at three levels: $\$ 0.15$, $\$ 0.30$, and $\$ 0.60$. While none of these amounts were large compared to the subjects' endowment, the absolute magnitude of the loss could be significant. For example, a one percent probability of a loss and a $\$ 0.60$ expected value of a loss imply a one percent chance of losing the entire $\$ 60$ earned from the initial earnings task described below.

Combining our choices for load, expected value of loss, and probability of loss, yields the 18 decisions shown in Table 2, and each subject faced all 18 decisions. This represents a withinsubjects full-factorial design of our three primary factors: the loss probability $(0.01,0.10)$, the expected value of the loss $(\$ 0.15, \$ 0.30, \$ 0.60)$, and the load $(0.8,1.0,4.0)$. We describe the exact procedures below.

Finally, we wanted to test whether using real payments mattered, so we conducted some sessions 
with hypothetical payments. The hypothetical payment sessions were conducted in an identical manner to the real-payment sessions with two exceptions: the statement subjects initialed after receiving the $\$ 10$ participation payment did not mention losses, and before the insurance task subjects received the following written information:

In this part of the experiment, the instructions will describe a series of gambling games. Each game has the possibility of a negative outcome. Each allows you to buy insurance against the negative outcome, although it is not required.

In fact, you will not actually lose any money and I will not take any payment from you in any of these games. Instead, I am going to ask you to consider each of them and tell me how you would play were the earnings described real. Try to take each as seriously as possible, even though nothing is at stake. We will do everything exactly as described in the instructions except that we will not take any money from you under any circumstances.

Please initial this sheet of paper to indicate that you understand that all earnings (losses and payments) are hypothetical for this portion of the experiment and that you will not lose any of the money you earned based on your choices in this part of the experiment.

The final factor (real versus hypothetical earnings) was administered between-subjects; in other words, a given subject faced all 18 decisions under either real payments or hypothetical payments. Table 3 summarizes the experimental design. We later conducted two additional sessions $(\mathrm{n}=31)$ with different load values that we describe in Section 5 .

\subsection{Experimental Procedures}

The experiment consists of a sequence of three phases: the induction, the earnings task, and the insurance task. In the induction, all subjects were seated in the lab, signed a consent form, were paid a $\$ 10$ participation payment, and signed a receipt form for this participation payment. As described earlier, subjects were instructed to put away this money and told they were free to leave with this payment or continue with the rest of the experiment.

For the earnings task, subjects took a general-knowledge quiz (see Appendix B) and their experiment endowments were determined by their score on the quiz. The subject received $\$ 60$ if she answered eight or more questions correctly on the quiz, otherwise she earned $\$ 30$. This performance-based payment was used to reinforce the idea that the subject had earned the money

(and not just given the money by the experimenter). However, to avoid confounding the effects of knowledge and initial endowment, the questions were chosen so that most subjects were expected 
to earn $\$ 60 .^{3}$ After quizzes were graded, we came to each subject individually to pay quiz earnings privately, in cash. Subjects were encouraged to count the money, and were instructed to leave their earnings on their desk until the end of the experimental session.

After this initial stake was earned, subjects participated in the insurance task. Instructions were distributed to all subjects (see Appendix C). Subjects were given a chance to read these instructions on their own, and then they were read aloud. Subjects completed the 18 insurance purchase decisions shown in Table 2. In each decision (called a "gamble" in the instructions, as in Slovic et al.), subjects were told the number of orange and white balls that would be used, the loss if an orange ball were drawn, and the price of insurance. Each subject was given a black pen and instructed to mark on the decision sheet to indicate whether she wished to purchase insurance in this situation. The decision sheets were given to subjects one at a time, with the order of presentation varied randomly for each subject. After completing a decision, subjects were instructed to put their decision sheet into a legal-sized envelope; when everyone had done so, the next decision sheet was handed out. Thus, after making a decision, the subject was not able to review or revise any previously-viewed decision.

After everyone had completed all 18 decisions, the black pens were collected and blue pens handed out. ${ }^{4}$ Subjects were then told to review all 18 decisions. If a subject wanted to change any of her decisions, she was told to indicate this on the form with the blue pen. Subjects did not know in advance that they would be given an opportunity to review any of their decisions. By changing the color of the pen, we were able to determine whether any subjects changed any decisions at this stage of the experiment after they had seen all 18 gambles.

After all decisions had been reviewed, they were placed back in the folder and the blue pens were collected. The experimenter then chose one of these 18 decisions as the binding decision for payment by drawing a numbered ping-pong ball from a bingo cage. In the instructions, subjects were told that we would look at only one randomly-selected decision when determining payment and that none of their other decisions would have any impact on their earnings. All decision sheets were collected, except for the one chosen for payment. Red pens were then distributed. Each subject was given a final opportunity to review her choice for this one selected gamble before the outcome was

\footnotetext{
${ }^{3}$ All but one subject earned $\$ 60$. The remaining subject was omitted from this analysis.

${ }^{4}$ These revision procedures follow Harbaugh et al. (2005).
} 
determined. As before, subjects were not told in advance that they would have this opportunity to review and change their choice in the selected gamble. After all subjects had reviewed their choice in the binding decision, the experimenter came to each subject to see if she had chosen to purchase insurance. If insurance was purchased, the experimenter collected the insurance premium out of the subject's quiz earnings. The appropriate number of orange and white ping-pong balls were counted and placed in the bingo cage in plain view of all subjects. The color of the ball drawn determined whether a loss occurred. If an orange ball was drawn, the experimenter came to each person to collect the loss (unless the subject had purchased insurance). Subjects then completed a short demographic questionnaire, filled out a receipt form for experiment earnings, and left the laboratory.

The experiment, including payment, lasted approximately 90 minutes. A total of 37 subjects participated in the hypothetical-payment sessions, and 40 subjects participated in the real-payment sessions. In the hypothetical-payment sessions, no money was collected from those who purchased insurance and losses were not collected from uninsured subjects after the realization of a loss event.

\section{Results}

We first present a graphical overview of our data and results from non-parametric statistical tests. After this, we present results from econometric analysis, and then we discuss subjects' decision switching behavior.

Because each subject completed all 18 decisions, the data for the statistical analysis are matched pairs (each subject serves as her own control). We use McNemar's exact test statistic for paired proportions, which takes into account the exact number of discordant pairs (i.e., individuals whose choices differ for the two decisions under comparison). For example, when we test for the effect of a change in loss probability from 0.01 to 0.10 for fair insurance and an expected value of a loss of $\$ 0.15$, we look at the choice (insure or not) for each individual in each of these two treatments and see whether this individual switched from insuring to not (or vice versa).

Treatment averages (the percentage of subjects purchasing insurance) and the corresponding test statistics are shown in Table 4, while Figure 2 presents this information in graphical form. Each panel of the figure presents the proportion of subjects who chose to purchase insurance when the 
probability of a loss was 0.01 (left point) and 0.10 (right point). The left column of this figure shows the data for subsidized insurance (load $=0.8$ ), the middle column shows data for fair insurance $($ load $=1.0)$ and the right column shows data for profitable insurance $($ load $=4.0)$. The expected value of a loss increases from $\$ 0.15$ in the top row of panels to $\$ 0.60$ in the bottom row of panels.

The middle column of this figure corresponds to the Slovic et al. experiment which used fair insurance. For comparison purposes we have included data from our Slovic et al. replication experiment in each of these three panels as a dotted line. This dotted line has a positive slope: the proportion of subjects buying insurance was lower for a loss probability of 0.01 than for a loss probability of 0.10 .

We see that the behavioral pattern of purchasing more insurance as the loss probability increases is not replicated in any of our treatments, except in the hypothetical treatment, when fair insurance is offered against a low $(\$ 0.15)$ expected value of a loss (for this data pair the proportion buying increases only slightly from 0.49 to 0.54 ). In fact, to the extent that the probability of a loss affects insurance purchasing behavior in this new experiment, the proportion purchasing is lower when the probability of a loss is 0.10 compared to 0.01 . As indicated by the asterisks in the figure, this difference is significant for most comparisons in the real-payment treatment. The only exceptions are for the largest losses: when the expected value of a loss is $\$ 0.60$ and the insurance is subsidized or fair, 90 percent of all subjects in the real-payment sessions purchase insurance regardless of the loss probability. However, when the insurance carries a high load, significantly more subjects insure when the loss probability is 0.01 than when it is 0.10 .

In the hypothetical payment sessions, fewer subjects purchase insurance than in the corresponding real payment sessions. And while the pattern of purchase decisions is similar to that in the real-payment sessions, the difference in the proportion of subjects buying insurance as the loss probability changes is generally not significantly different than zero.

\subsection{Panel Probit Results}

We also estimate a panel probit regression model of insurance purchase and the results are consistent with the nonparametric analysis presented above. The regression assumes a threshold crossing model in which individuals purchase insurance when the net benefit is positive. For a risk-averse expected-utility maximizer, the net benefit of insurance increases in the probability of loss (holding 
the expected loss constant). Random effects are included to allow for unobserved individual differences that may affect the propensity to insure but are assumed to be uncorrelated with treatment parameters due to the randomized design. We estimate separate models for hypothetical- and real-payment sessions, as well as a pooled specification with an indicator variable for the type of incentives and a full set of interactions for hypothetical incentives. We also report regressions that include individual demographic and insurance purchase data gathered from the post-experiment questionnaire.

The regression results in Table 5 show that the probability of purchasing insurance is positively and significantly related to the probability of loss holding expected loss and load constant. Hypothetical incentives significantly reduce the likelihood of purchasing insurance and mitigate the sensitivity to the probability of loss. The regression results in Table 5 also show that load and the magnitude of the expected loss affect purchase rates. Under both real and hypothetical incentives, subjects responded rationally to increases in the load by decreasing purchase rates. We also see that subjects were more likely to insure against larger expected losses than smaller ones, but the effect was greater when the incentives were real.

After completing the experiment, subjects were asked to fill out a short questionnaire asking about their demographic characteristics and whether or not they had purchased common forms of insurance and extended warranties. The descriptive statistics for their responses are shown in Appendix D. Adding this demographic and insurance purchase experience to the regressions made little difference to the main results. Age was the only variable found to have a significant effect on purchase rates. Larger samples may be needed in order to identify the relationships between the decision to insure in the lab and demographic characteristics or other (naturally occurring) insurance purchases. Recent studies linking field behavior to risk aversion and discount rates have found that sample sizes on the order of five times ours are needed for sufficient power (Anderson \& Mellor, 2007; Chabris et al., 2008).

\subsection{Analysis of Switching Behavior}

After making their initial decision, subjects were given two opportunities to change their decision: when reviewing all decisions and after the binding decision was chosen (at which time only the binding decision could be changed). An analysis of these changes gives us some insight into how 
incentives affect behavior. First we found there was a surprising amount of switching: about half of all subjects changed at least one of their decisions. In total, 7 percent and 6.7 percent of all decisions were changed in the real-and hypothetical-incentives treatments, respectively. In the real-payment treatment, most switches (75 percent) were from not buying insurance to buying insurance while the switches in the hypothetical-payment sessions were about evenly split (52 percent from not buying to buying).

Because changes in the purchase decision may represent corrections of recording errors or learning over the course of the experiments, the revised decisions may be less noisy. Using the initial decisions does not alter our qualitative conclusions, but does shed light on the different impact of real and hypothetical treatments. When only one decision of eighteen will count, subjects may not fully take into account the incentives when making their initial choices. When they are given the chance to review decisions, they are reminded that the draw is eminent and the incentives are more focal. With hypothetical incentives, the decision changes go both ways, but with real incentives, the rate of insurance purchase rises and the difference between real and hypothetical incentives widens. This interpretation is consistent with the literature showing that hypothetical incentives may lead to increased variance and that risk aversion increases with stakes (Holt \& Laury, 2002, 2005; Harrison et al., 2005; Camerer \& Hogarth, 1999).

\section{Robustness Checks}

At the suggestion of a referee, we conducted an additional experiment with more realistic loads. This experiment was structured the same as the prior experiment, except the load levels were changed to be $1.5,2$, and 3 . In total, 31 new subjects participated for real payment in two sessions. All results in the new experiment were consistent with our prior findings: insurance purchase was generally high, and subjects purchased more insurance when the probability of loss was 0.01 than 0.1 .

Table 6 reports the proportion of insurance purchase for each combination of probability of loss, load, and expected loss. For every combination of load and expected loss, we see that insurance purchase is greater for the one percent event than the ten percent event. In five of the nine cases, a two-sided McNemar test shows this difference as statistically significant at the five percent level 
(and two additional cases show p-values of 0.063 and 0.065). Figure 3 graphically presents this information.

Table 7 provides the results of random effects probit regressions for the probability of insurance purchase. We first examine the new treatments separately (column 1), then pool all real incentive treatments (column 2), and finally pool all data (column 3). Comparing the results in Table 7 to those in Table 5, we see consistent results with the exception of load. Load has the same sign but is not statistically significant for the new treatments alone. Given the narrow range of loads in the new treatments relative to the original treatments, such a result is not surprising. Our main conclusion remains unchanged and contrary to the prior literature: for these experiments and parameter values, we find that insurance purchase is higher for low-probability, high-loss events relative to higher-probability, lower-loss events.

We also added an open ended question to the demographic questionnaire given at the end of the experiment: "What factors influenced your decisions about whether to buy insurance or not buy insurance in the gambles you faced in today's experiment?" We summarized the factors mentioned and found that 19 of the 31 subjects mentioned only one factor. Of those, 7 mentioned a preference for certainty or aversion to risk (for example, "I feel like it is always better to be safe," or "... I opted for insurance each time, unwilling to chance losing any, even at 99 percent odds ..."). The remainder mentioned the amount of the loss (5 of 19), the probability of loss (3 of 19), or some other reason (4 of 19). None of the responses cited the premium as the sole factor influencing the decision. In the 12 responses that cited multiple factors, 4 mention certainty or risk aversion, 9 mention the size of loss, 8 mention the premium, and 7 mention the probability. One interesting feature of the responses is that they suggest we were successful in framing decisions in terms of losses. None of the responses re-frame the gambles in terms of choices over gains, and several suggest the gambles were viewed as non-trivial losses of earnings (for example, "I was motivated by the desire to keep as much of my original $\$ 60$ as possible" and "I bought insurance for all decisions because I do not like to gamble with anything of importance or value ..."). 


\section{Conclusions}

It has been widely accepted that individuals tend to under-insure against low-probability, high-loss events relative to high-probability, low-loss events. When people fail to insure against catastrophic losses, the social and economic costs of this can be quite large. If our goal is to develop a policy solution to this problem, it is important to understand why so many people fail to purchase this insurance. For example, if consumers do not process low probabilities accurately, then offering bundled policies may remedy the problem. On the other hand, if they do not insure because the insurance is too expensive (or carries too high of a load), then offering credible, subsidized insurance should help.

In this experiment, we implemented real, high-consequence losses in the laboratory. Our focus was on how individuals respond to changes in the probability of a loss. The conventional wisdom is that people misperceive probabilities and fail to distinguish between low-probability events and those with zero probability. This conventional wisdom and prior experimental evidence predicted that subjects would purchase less insurance with a loss probability of one percent than with a loss probability of ten percent. In contrast, our results suggest that the sensitivity to the probability of loss depends on the way the loss is framed and whether incentives are real or hypothetical. We find no evidence of underinsurance of low probability losses when incentives are real and large. Therefore a policy focusing on probability misperceptions may be fundamentally misguided and may not solve the problem of under-insurance in the field. Instead, policies focusing on other explanations for under-insurance (moral hazards and high loads, for example) may be more successful.

Our experiments indicate several areas of future research. Our results show that if there is an attention threshold for risk, it is variable across individuals and decision contexts. Slovic et al. (1977) noted that more work was needed to understand whether variables other than probability affected the risk threshold, and new models of insurance purchase behavior proposed by Kunreuther \& Pauly (2004), Kunreuther \& Pauly (2005), and Krantz \& Kunreuther (2007) suggest several interesting testable hypotheses about how context may affect attention threshold in risky decisions. In addition, Krantz \& Kunreuther suggest using maximum loads that individuals are willing to accept as a way to test between alternative models of decisionmaking. Our results here show that

load has a strong effect on purchase rates, but our experiments were not designed to elicit the 
critical values for load required to run the horse race between alternative decision models. 


\section{References}

Anderson, D. R. (1974). The national flood insurance program: Problems and potential. Journal of Risk and Insurance, 41, 579-599.

Anderson, L., \& Mellor, J. (2007). Predicting health behaviors with experimental measures of risk aversion. Technical report, Department of Economics, College of William and Mary.

Camerer, C. F., \& Hogarth, R. M. (1999). The effects of financial incentives in experiments: A review and capital-labor-production framework. Journal of Risk and Uncertainty, 19, 7-42.

Chabris, C. F., Laibson, D., Morris, C. L., Schuldt, J. P., \& Taubinsky, D. (2008). Individual laboratory-measured discount rates predict field behavior. Technical report, National Bureau of Economic Research.

Ganderton, P. T., Brookshire, D. S., McKee, M., Stewart, S., \& Thurston, H. (2000). Buying insurance for disaster-type risks: Experimental evidence. Journal of Risk and Uncertainty, 20, $271-289$.

Harbaugh, W., Krause, K., \& Vesterlund, L. (2005). The fourfold pattern of risk attitudes in choice and pricing tasks. Working paper, University of Pittsburgh, Department of Economics.

Harrington, S. E., \& Niehaus, G. (2003). Capital, corporate income taxes, and catastrophe insurance. Journal of Financial Intermediation, 12, 365-389.

Harrison, G. W., Johnson, E., Mcinnes, M. M., \& Rutström, E. E. (2005). Risk aversion and incentive effects: Comment. American Economic Review, 95, 897-901.

Holt, C. A., \& Laury, S. K. (2002). Risk aversion and incentive effects. American Economic Review, 92, 1644-1655.

Holt, C. A., \& Laury, S. K. (2005). Risk aversion and incentive effects: New data without order effects. American Economic Review, 95, 902-912.

Krantz, D. H., \& Kunreuther, H. C. (2007). Goals and plans in decision making. Judgement and Decision Making, 2, 137-168. 
Kunreuther, H., Novemsky, N., \& Kahneman, D. (2001). Making low probabilities useful. Journal of Risk and Uncertainty, 23, 103-120.

Kunreuther, H., \& Pauly, M. (2004). Neglecting disaster: Why don't people insure against large losses? Journal of Risk and Uncertainty, 28, 5-21.

Kunreuther, H., \& Pauly, M. (2005). Insurance decision-making and market behavior. Foundations and trends in microeconomics, 1, 63-127.

McClelland, G. H., Schulze, W. D., \& Coursey, D. L. (1993). Insurance for low-probability hazards: A bimodal response to unlikely events. Journal of Risk and Uncertainty, 7, 95-116.

Pauly, M., Percy, A., \& Herring, B. (1999). Individual versus job-based health insurance: weighing the pros and cons. Health Affairs, 18, 28-44.

Slovic, P., Fischhoff, B., Lichtenstein, S., Corrigan, B., \& Combs, B. (1977). Preference for insuring against probable small losses: Insurance implications. Journal of Risk and Insurance, 44, 237-258.

Tversky, A., \& Kahneman, D. (1992). Advances in prospect theory: Cumulative representation of uncertainty. Journal of Risk and Uncertainty, 5, 297-323. 
Table 1: Percent buying insurance for Slovic et al. replication.

\begin{tabular}{cccccccc}
\hline $\begin{array}{c}\text { \# orange } \\
\text { balls }\end{array}$ & $\begin{array}{c}\text { \# white } \\
\text { balls }\end{array}$ & $\begin{array}{c}\text { Loss } \\
\text { Probability }\end{array}$ & $\begin{array}{c}\text { Loss } \\
\text { Amount }\end{array}$ & $\begin{array}{c}\text { EV } \\
\text { Loss }\end{array}$ & $\begin{array}{c}\text { Insurance } \\
\text { Price }\end{array}$ & $\begin{array}{c}\text { Slovic } \\
\text { Data* }\end{array}$ & $\begin{array}{c}\text { Replication } \\
\text { Data }\end{array}$ \\
\hline 1 & 9999 & 0.0001 & 10,000 & 1 & 1 & $16 \%$ & $26 \%$ \\
10 & 9990 & 0.001 & 1,000 & 1 & 1 & $12 \%$ & $29 \%$ \\
50 & 9950 & 0.005 & 200 & 1 & 1 & $19 \%$ & $41 \%$ \\
100 & 9900 & 0.01 & 100 & 1 & 1 & $25 \%$ & $47 \%$ \\
500 & 9500 & 0.05 & 20 & 1 & 1 & $48 \%$ & $59 \%$ \\
1000 & 9000 & 0.1 & 10 & 1 & 1 & $64 \%$ & $62 \%$ \\
2500 & 7500 & 0.25 & 4 & 1 & 1 & $69 \%$ & $71 \%$ \\
5000 & 5000 & 0.5 & 2 & 1 & 1 & $62 \%$ & $68 \%$ \\
\hline
\end{tabular}

*These data are an estimate of their results based on their figure. 
Table 2: Experiment 2 insurance scenarios.

\begin{tabular}{ccccc}
\hline Prob(Loss) & EV(Loss) & Insurance Load & Loss Amount & Insurance Premium \\
\hline 0.01 & 0.15 & 0.8 & $\$ 15.00$ & $\$ 0.12$ \\
0.01 & 0.15 & 1 & $\$ 15.00$ & $\$ 0.15$ \\
0.01 & 0.15 & 4 & $\$ 15.00$ & $\$ 0.60$ \\
0.01 & 0.30 & 0.8 & $\$ 30.00$ & $\$ 0.24$ \\
0.01 & 0.30 & 1 & $\$ 30.00$ & $\$ 0.30$ \\
0.01 & 0.30 & 4 & $\$ 30.00$ & $\$ 1.20$ \\
0.01 & 0.60 & 0.8 & $\$ 60.00$ & $\$ 0.48$ \\
0.01 & 0.60 & 1 & $\$ 60.00$ & $\$ 0.60$ \\
0.01 & 0.60 & 4 & $\$ 60.00$ & $\$ 2.40$ \\
0.1 & 0.15 & 0.8 & $\$ 1.50$ & $\$ 0.12$ \\
0.1 & 0.15 & 1 & $\$ 1.50$ & $\$ 0.15$ \\
0.1 & 0.15 & 4 & $\$ 1.50$ & $\$ 0.60$ \\
0.1 & 0.30 & 0.8 & $\$ 3.00$ & $\$ 0.24$ \\
0.1 & 0.30 & 1 & $\$ 3.00$ & $\$ 0.30$ \\
0.1 & 0.30 & 4 & $\$ 3.00$ & $\$ 1.20$ \\
0.1 & 0.60 & 0.8 & $\$ 6.00$ & $\$ 0.48$ \\
0.1 & 0.60 & 1 & $\$ 6.00$ & $\$ 0.60$ \\
0.1 & 0.60 & 4 & $\$ 6.00$ & $\$ 2.40$ \\
\hline
\end{tabular}


Table 3: Experiment 2 summary of treatments and sample sizes.

\begin{tabular}{l|l|c}
\hline \multicolumn{2}{c}{} & \multicolumn{2}{c}{ across subjects } \\
\cline { 2 - 3 } within subjects & \multicolumn{1}{c}{$\begin{array}{l}\text { real } \\
\text { payment } \\
\text { expected loss }(\$ 0.15, \$ 0.30, \$ 0.60) \\
\text { load }(0.8,1,4)\end{array}$} & $\begin{array}{c}\text { hypothetical } \\
\text { payment }\end{array}$ \\
\cline { 2 - 3 } & 40 subjects & 37 subjects \\
\hline
\end{tabular}


Table 4: Experiment 2 insurance purchase percentages.

\begin{tabular}{|c|c|c|c|c|c|c|c|}
\hline \multirow[b]{2}{*}{$\begin{array}{l}\text { Insurance } \\
\text { load }\end{array}$} & \multirow[b]{2}{*}{$\begin{array}{l}\text { Loss } \\
\text { prob }\end{array}$} & \multirow[b]{2}{*}{$\begin{array}{c}\text { Loss } \\
\text { amount }\end{array}$} & \multirow[b]{2}{*}{$\begin{array}{l}\text { EV } \\
\text { loss }\end{array}$} & \multicolumn{2}{|c|}{ Hypothetical Payment } & \multicolumn{2}{|c|}{ Real Payment } \\
\hline & & & & $\begin{array}{c}\text { Percent } \\
\text { buying }\end{array}$ & $\begin{array}{l}\text { McNemar } \\
(\mathrm{p} \text {-value })\end{array}$ & $\begin{array}{l}\text { Percent } \\
\text { buying }\end{array}$ & $\begin{array}{c}\text { McNemar } \\
\text { (p-value) }\end{array}$ \\
\hline \multirow{6}{*}{$\begin{array}{c}0.8 \\
\text { (subsidized) }\end{array}$} & 0.01 & 15.00 & 0.15 & $62 \%$ & \multirow{2}{*}{$\begin{array}{l}-0.905 \\
(0.549)\end{array}$} & $88 \%$ & \multirow{2}{*}{$\begin{array}{l}-2.668 \\
(0.013)\end{array}$} \\
\hline & 0.1 & 1.50 & 0.15 & $54 \%$ & & $60 \%$ & \\
\hline & 0.01 & 30.00 & 0.30 & $65 \%$ & \multirow{2}{*}{$\begin{array}{l}-1.000 \\
(0.455)\end{array}$} & $90 \%$ & \multirow{2}{*}{$\begin{array}{l}-2.324 \\
(0.035)\end{array}$} \\
\hline & 0.1 & 3.00 & 0.30 & $54 \%$ & & $68 \%$ & \\
\hline & 0.01 & 60.00 & 0.60 & $68 \%$ & \multirow{2}{*}{$\begin{array}{c}0.000 \\
(1.000)\end{array}$} & $90 \%$ & \multirow{2}{*}{$\begin{array}{c}0.000 \\
(1.000)\end{array}$} \\
\hline & 0.1 & 6.00 & 0.60 & $68 \%$ & & $90 \%$ & \\
\hline \multirow{6}{*}{$\begin{array}{c}1 \\
\text { (fair) }\end{array}$} & 0.01 & 15.00 & 0.15 & $49 \%$ & \multirow{2}{*}{$\begin{array}{c}0.580 \\
(0.774)\end{array}$} & $85 \%$ & \multirow{2}{*}{$\begin{array}{l}-2.840 \\
(0.007)\end{array}$} \\
\hline & 0.1 & 1.50 & 0.15 & $54 \%$ & & $58 \%$ & \\
\hline & 0.01 & 30.00 & 0.30 & $51 \%$ & \multirow{2}{*}{$\begin{array}{c}-0.302 \\
(1.000)\end{array}$} & $90 \%$ & \multirow{2}{*}{$\begin{array}{l}-2.324 \\
(0.035)\end{array}$} \\
\hline & 0.1 & 3.00 & 0.30 & $49 \%$ & & $68 \%$ & \\
\hline & 0.01 & 60.00 & 0.60 & $59 \%$ & \multirow{2}{*}{$\begin{array}{c}0.000 \\
(1.000)\end{array}$} & $90 \%$ & \multirow{2}{*}{$\begin{array}{c}0.000 \\
(1.000)\end{array}$} \\
\hline & 0.1 & 6.00 & 0.60 & $59 \%$ & & $90 \%$ & \\
\hline \multirow{6}{*}{4} & 0.01 & 15.00 & 0.15 & $46 \%$ & \multirow{2}{*}{$\begin{array}{l}-1.732 \\
(0.146)\end{array}$} & $85 \%$ & \multirow{2}{*}{$\begin{array}{l}-4.583 \\
(0.000)\end{array}$} \\
\hline & 0.1 & 1.50 & 0.15 & $30 \%$ & & $33 \%$ & \\
\hline & 0.01 & 30.00 & 0.30 & $41 \%$ & \multirow{2}{*}{$\begin{array}{l}-2.646 \\
(0.016)\end{array}$} & $83 \%$ & \multirow{2}{*}{$\begin{array}{l}-3.771 \\
(0.000)\end{array}$} \\
\hline & 0.1 & 3.00 & 0.30 & $22 \%$ & & $43 \%$ & \\
\hline & 0.01 & 60.00 & 0.60 & $49 \%$ & \multirow{2}{*}{$\begin{array}{l}-2.111 \\
(0.065)\end{array}$} & $85 \%$ & \multirow{2}{*}{$\begin{array}{l}-3.153 \\
(0.003)\end{array}$} \\
\hline & 0.1 & 6.00 & 0.60 & $30 \%$ & & $53 \%$ & \\
\hline
\end{tabular}


Table 5: Experiment 2 random effects probit models of the probability of purchasing insurance. Standard errors in parentheses.

\begin{tabular}{|c|c|c|c|}
\hline Coefficient & $\begin{array}{l}\text { Hypothetical } \\
\text { payment }\end{array}$ & $\begin{array}{c}\text { Real } \\
\text { payment }\end{array}$ & Pooled \\
\hline Prob(Loss) & $\begin{array}{l}-3.586 \\
(1.364)^{* *}\end{array}$ & $\begin{array}{l}-14.068 \\
(1.612)^{* *}\end{array}$ & $\begin{array}{r}-14.282 \\
(1.608)^{* *}\end{array}$ \\
\hline Load & $\begin{array}{l}-0.291 \\
(0.044)^{* *}\end{array}$ & $\begin{array}{l}-0.277 \\
(0.045)^{* *}\end{array}$ & $\begin{array}{c}-0.282 \\
(0.046)^{* *}\end{array}$ \\
\hline $\mathrm{EV}(\mathrm{Loss})$ & $\begin{array}{c}0.673 \\
(0.328)^{*}\end{array}$ & $\begin{array}{l}1.700 \\
(0.365)^{* *}\end{array}$ & $\begin{array}{l}1.727 \\
(0.367)^{* *}\end{array}$ \\
\hline Hypothetical & & & $\begin{array}{l}-1.420 \\
(0.412)^{* *}\end{array}$ \\
\hline $\begin{array}{c}\text { Interaction: } \\
\text { Hyp } \times \text { EV(Loss })\end{array}$ & & & $\begin{array}{l}-1.065 \\
(0.489)^{*}\end{array}$ \\
\hline $\begin{array}{l}\text { Inteaction: } \\
\text { Hyp } \times \text { Load }\end{array}$ & & & $\begin{array}{c}-0.004 \\
(0.062)\end{array}$ \\
\hline $\begin{array}{c}\text { Interaction: } \\
\text { Hyp } \times \text { Prob(Loss) }\end{array}$ & & & $\begin{array}{l}10.750 \\
(2.095)^{* *}\end{array}$ \\
\hline Constant & $\begin{array}{c}0.565 \\
(0.305)\end{array}$ & $\begin{array}{l}1.918 \\
(0.289)^{* *}\end{array}$ & $\begin{array}{l}1.973 \\
(0.302)^{* *}\end{array}$ \\
\hline Observations & 666 & 720 & 1386 \\
\hline Number of Subjects & 37 & 40 & 77 \\
\hline
\end{tabular}


Table 6: Experiment 3 insurance purchase percentages.

\begin{tabular}{cccccc}
\hline & & & & \multicolumn{2}{c}{ Real Payment } \\
\cline { 5 - 6 } $\begin{array}{c}\text { Insurance } \\
\text { load }\end{array}$ & $\begin{array}{c}\text { Loss } \\
\text { prob }\end{array}$ & $\begin{array}{c}\text { Loss } \\
\text { amount }\end{array}$ & $\begin{array}{c}\text { EV } \\
\text { loss }\end{array}$ & $\begin{array}{c}\text { Percent } \\
\text { buying }\end{array}$ & $\begin{array}{c}\text { McNemar } \\
\text { (p-value) }\end{array}$ \\
\hline & 0.01 & 15.00 & 0.15 & $84 \%$ & -2.449 \\
& 0.1 & 1.50 & 0.15 & $65 \%$ & $(0.031)$ \\
1.5 & 0.01 & 30.00 & 0.30 & $94 \%$ & -2.333 \\
& 0.1 & 3.00 & 0.30 & $71 \%$ & $(0.039)$ \\
& 0.01 & 60.00 & 0.60 & $97 \%$ & -2.236 \\
& 0.1 & 6.00 & 0.60 & $81 \%$ & $(0.063)$ \\
\hline & 0.01 & 15.00 & 0.15 & $81 \%$ & -1.667 \\
2 & 0.1 & 1.50 & 0.15 & $65 \%$ & $(0.180)$ \\
& 0.01 & 30.00 & 0.30 & $90 \%$ & -2.111 \\
& 0.1 & 3.00 & 0.30 & $68 \%$ & $(0.0654)$ \\
& 0.01 & 60.00 & 0.60 & $97 \%$ & -3.000 \\
& 0.1 & 6.00 & 0.60 & $68 \%$ & $(0.004)$ \\
\hline \multirow{3}{*}{3} & 0.01 & 15.00 & 0.15 & $81 \%$ & -2.646 \\
& 0.1 & 1.50 & 0.15 & $58 \%$ & $(0.016)$ \\
& 0.01 & 30.00 & 0.30 & $94 \%$ & -2.333 \\
& 0.1 & 3.00 & 0.30 & $71 \%$ & $(0.039)$ \\
& 0.01 & 60.00 & 0.60 & $94 \%$ & -1.890 \\
& 0.1 & 6.00 & 0.60 & $77 \%$ & $(0.125)$ \\
\hline
\end{tabular}


Table 7: Experiment 3 random effects probit models of the probability of purchasing insurance. Standard errors in parentheses.

\begin{tabular}{cccc}
\hline Coefficient & $\begin{array}{c}\text { New real } \\
\text { payment }\end{array}$ & $\begin{array}{c}\text { All real } \\
\text { payment }\end{array}$ & $\begin{array}{c}\text { Pooled } \\
\text { hyp. and real }\end{array}$ \\
\hline Prob(Loss) & -19.506 & -15.684 & -15.615 \\
& $(2.582)^{* *}$ & $(1.362)^{* *}$ & $(1.348)^{* *}$ \\
Load & -0.142 & -0.281 & -0.279 \\
& $(0.157)$ & $(0.044)^{* *}$ & $(0.044)^{* *}$ \\
EV(Loss) & 2.478 & 1.919 & 1.910 \\
& $(0.566)^{* *}$ & $(0.304)^{* *}$ & $(0.303)^{* *}$ \\
Hypothetical & & & -1.744 \\
& & & $(0.416)^{* *}$ \\
Interaction: & & & -1.233 \\
Hyp $\times$ EV(Loss) & & & $(0.446)^{* *}$ \\
Inteaction: & & & -0.013 \\
Hyp $\times$ Load & & & $(0.062)$ \\
Interaction: & & & 12.006 \\
Hyp $\times$ Prob(Loss $)$ & & & $(1.914)^{* *}$ \\
Constant & 3.131 & 2.338 & 2.315 \\
& $(0.673)^{* *}$ & $(0.283)^{* *}$ & $(0.272)^{* *}$ \\
\hline Observations & 558 & 1278 & 1944 \\
Number of Subjects & 31 & 71 & 108 \\
\hline$*$ Statisigl sicas & & & \\
\hline
\end{tabular}

* Statistical significance at the five percent level.

** Statistical significance at the one percent level. 


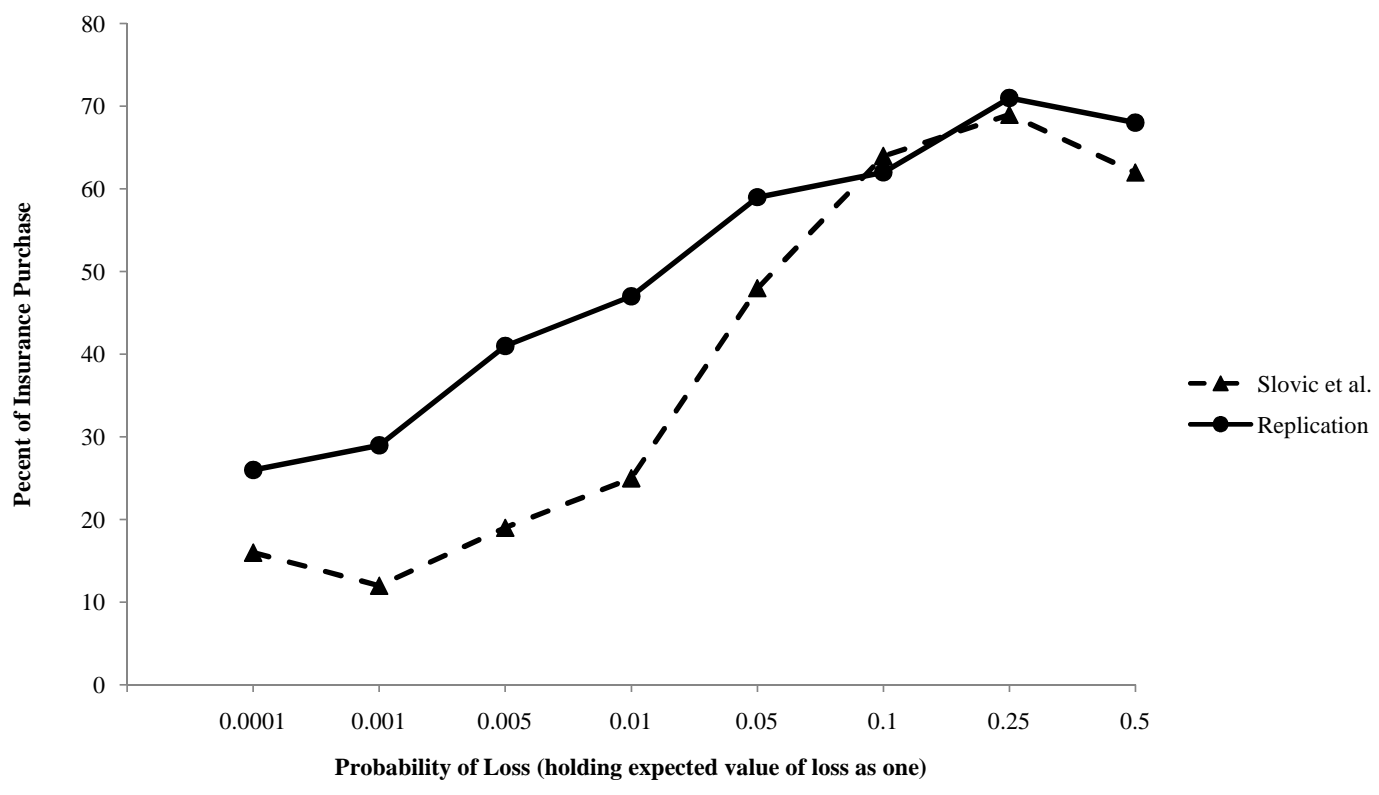

Figure 1: Comparison of results from Slovic et al. and our replication. 

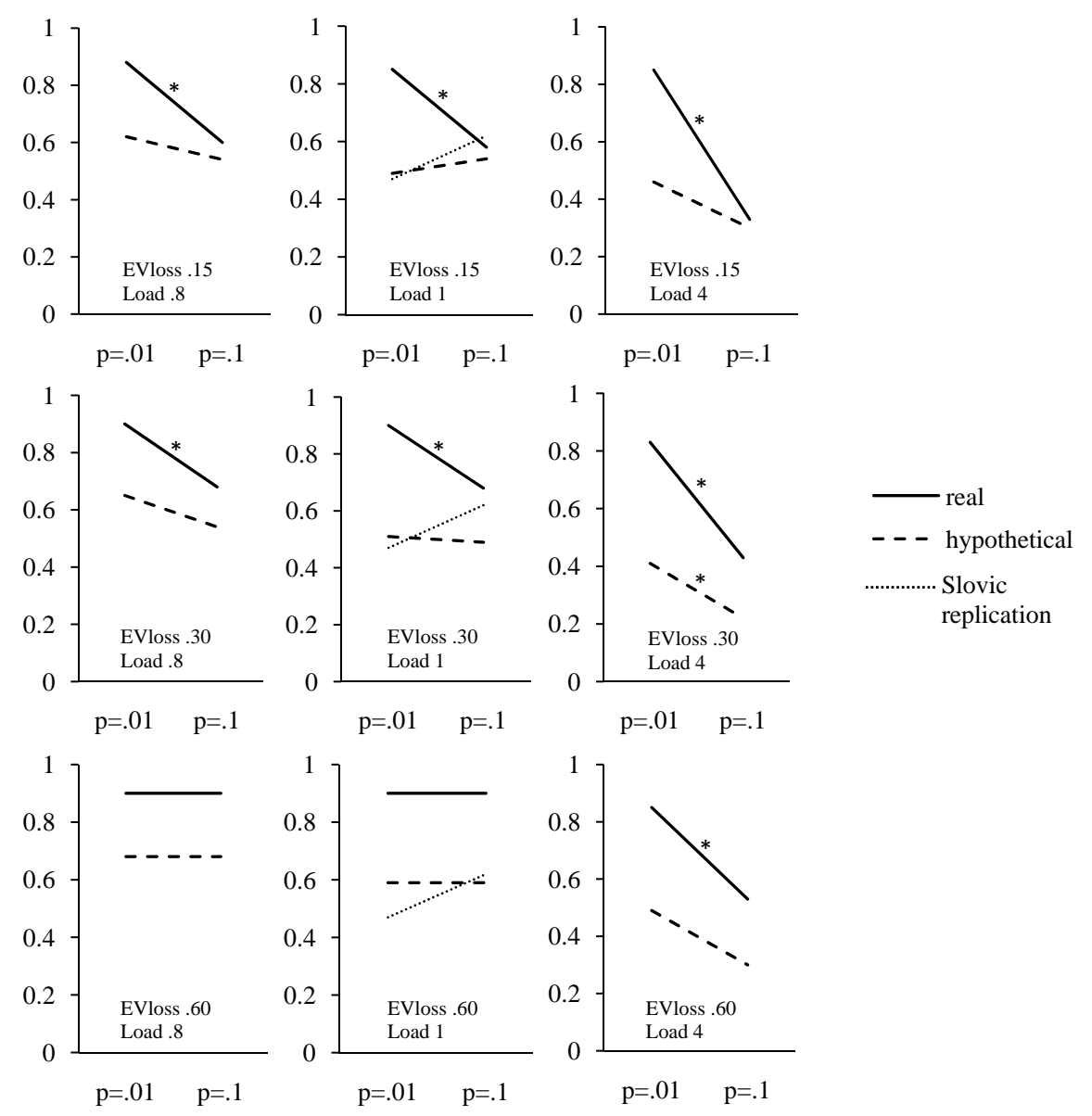

$0 \frac{\text { Load } 4}{p=.01 \quad p=.1}$

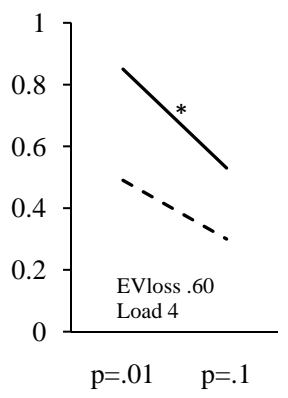

* Significant difference at the 5 percent level using a two-sided McNemar's test

Figure 2: Experiment 2 proportion of insurance purchases for loss probabilities 0.01 and 0.1, conditioned on expected loss and load. 

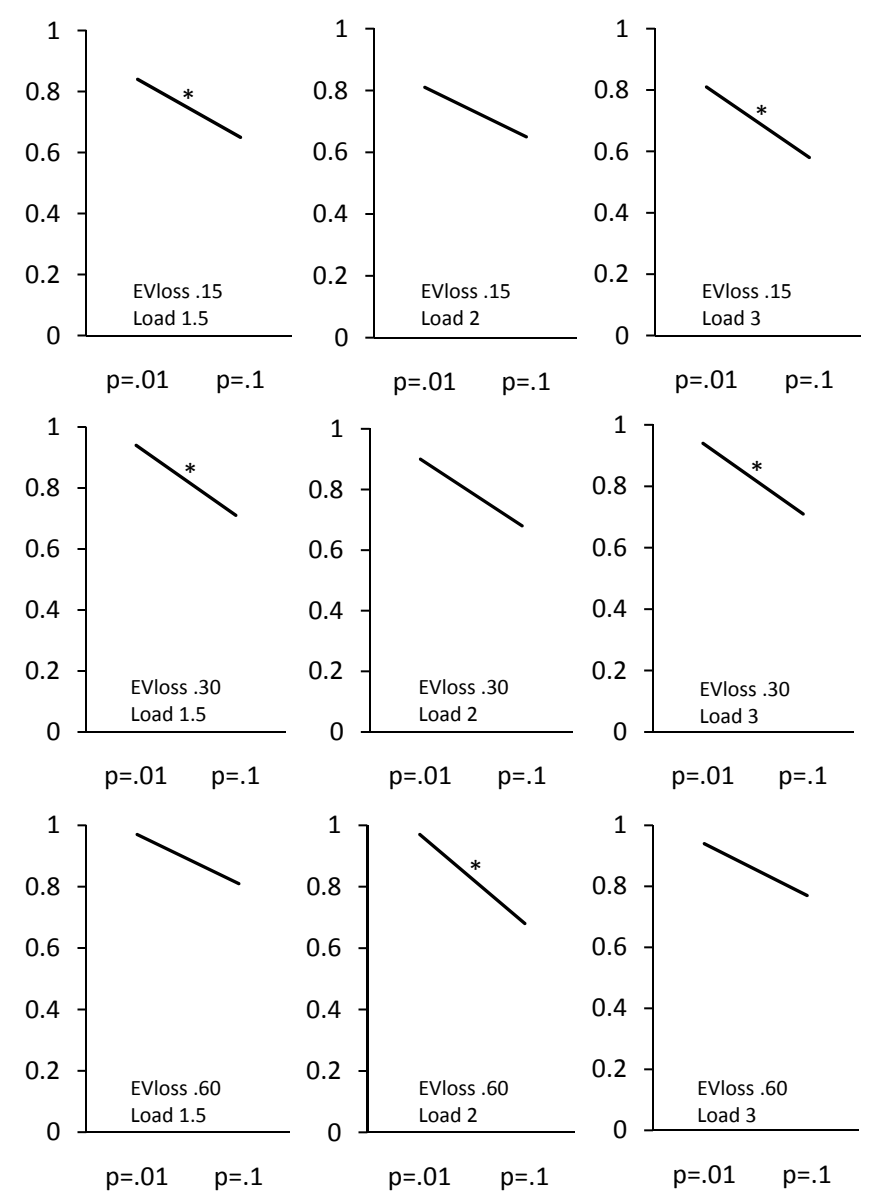

* Significant difference at the 5 percent level using a two-sided McNemar's test

Figure 3: Experiment 3 proportion of insurance purchases for one and ten percent loss events, conditioned on expected loss and load. 


\section{A Instructions for Slovic et al. Replication}

In this survey, I am going to describe a series of gambling games. Each game has the possibility of negative outcomes. Each allows you to buy insurance against the negative outcomes, although it is not required. I am not going to ask you to play any of the games. Instead, I am going to ask you to consider each and then tell me how you would play were they for real. Try to take each as seriously as possible, even though nothing is at stake.

Each game consists of drawing one ball from each set of baskets. Each contains a different mixture of orange and white balls. If I were to draw a white ball, no loss would occur. If I were to draw an orange ball, this would result a loss, unless you had purchased insurance. (Remember, we will not actually play any of these gambles, but I want you to think about each as if you were really going to play each one.)

As you can see, you can only lose in this sort of game (either by drawing an orange ball or by buying insurance). Your object is to lose as little as possible. For each game figure out what insurance you would buy to end up with the fewest negative points. 


\section{B General Knowledge Quiz}

The following questions test your knowledge of current events, American history, and geography. Please indicate the correct answer in the blank beside each question. You will be paid based on the number of questions you answer correctly.

If you answer 8 or more questions correctly, you will be paid $\$ 60$.

If you answer 7 or fewer questions correctly, you will be paid $\$ 30$

1. The current Secretary of State is
a. Dick Cheney
b. John Snow
c. Donald Rumsfeld
d. Condeleza Rice

2. The winner of the 2006 Superbowl was
a. Pittsburg Steelers
b. Indianapolis Colts
c. Carolina Panthers
d. Seattle Seahawks

3. Which of the following states borders the Gulf of Mexico?
a. California
b. Texas
c. Maine
d. North Carolina

4. Who was the last President to die in office?
a. John Kennedy
b. Bill Clinton
c. Gerald Ford
d. Ronald Reagan

5. What is the capital of Arkansas?
a. Pierre
b. Sacramento
c. Albany
d. Little Rock

6. Which of the following was one of the first 13 colonies?
a. Montana
b. Virginia
c. Louisiana
d. Texas

7. Who is the host of American Idol?
a. Howie Mandel
b. Regis Philben
c. Jeff Probst
d. Ryan Seacrest

8. Which of the following toys was named for a U.S. President?
a. Jacks
b. Raggedy Andy
c. Marco Polo
d. Teddy bear

9. "Only you can prevent forest fires." was the slogan of 

a. Toucan Sam
b. Polly the Parrot
c. Woodsy the $\mathrm{Owl}$
d. Smokey the Bear

10. Which of the following was an ally of the United States in World War II?
a. Germany
b. Switzerland
c. Italy
d. Great Britain

11. Which of the following is a movie about twin girls raised separately who meet at camp and eventually persuade their parents to reunite?
a. Freaky Friday
b. The Pajama Game
c. The Parent Trap
d. Yours, Mine and Ours

12. Which television network carries the OC?
a. Fox
b. PBS
c. $\mathrm{HBO}$
d. MTV

13. "Scrubs" is a television series centered around
a. a carwash
b. a hospital
c. a baseball team
d. hotel maid service

14. Who is credited with inventing the light bulb?
a. Eli Whitney
b. Oprah Winfrey
c. Thomas Edison
d. Enrico Marconi

15. "First in Flight" is the slogan of which of the following states?
a. Texas
b. Montana
c. Maine
d. North Carolina 


\section{Experiment Instructions}

Today you will make choices about a series of gambles. Each gamble has the possibility of a negative outcome. In each gamble, you will be allowed to buy insurance against the negative outcome, although you are not required to buy the insurance.

Each gamble consists of drawing one ball from a basket. Each basket contains a different mixture of orange and white balls. If I draw a white ball, no loss occurs. If I draw an orange ball, this will result in a loss. Any loss you incur will be paid out of the money you earned by taking the Current Events Quiz, unless you choose to purchase insurance.

Here is how this will work: if you choose to purchase insurance, you will pay for this out of the money that you earned by taking the Current Events Quiz. If you do not purchase insurance and I draw a white ball, you will keep all of the money that you earned. If you do not purchase insurance and I draw an orange ball, you will lose some or all of the money that you earned by taking the Current Events Quiz. Each gamble will specify how much you may lose and how much the insurance will cost.

Each gamble that you face will be similar to the following (though the numbers used in the experiment will be different than this example):

\begin{tabular}{|c|c|c|}
\hline \multicolumn{3}{|l|}{ Gamble 0} \\
\hline & Orange Balls & White Balls \\
\hline Number in Basket & 5 & 95 \\
\hline Loss if Drawn & $\$ 12.00$ & $\$ 0$ \\
\hline \multicolumn{3}{|c|}{ Insurance Premium: $\$ 12.00$} \\
\hline & Yes & No \\
\hline \multicolumn{3}{|c|}{ Do you want to purchase insurance for $\$ 1.20 ?$} \\
\hline \multicolumn{3}{|c|}{ Indicate your answer by placing an $\mathrm{X}$ in the appropriate box above. } \\
\hline \multicolumn{3}{|c|}{$\begin{array}{l}\text { If this is the gamble that is chosen: } 1 \text {. Only your insurance decision on this } \\
\text { sheet will be considered; and } 2 \text {. If you purchase insurance for this } \\
\text { gamble, you will pay for it before we draw a ball from this basket. }\end{array}$} \\
\hline
\end{tabular}

If you faced the gamble in this example and you chose to purchase insurance you would pay me $\$ 1.20$ from the money you earned by taking the Current Events Quiz. You would pay this $\$ 1.20$ before I drew a ball from the basket, so you would pay it regardless of whether I drew a white ball or an orange ball. However, if you purchased this insurance and I drew an orange ball, you would not lose $\$ 12$ in this example.

You will make decisions for 18 gambles during this part of the experiment. You should read the information provided to you in each one carefully: the number of orange and white balls, the loss you incur if an orange ball is drawn, and the insurance premium may change from one gamble to another.

Even though you will face 18 gambles in this experiment, only ONE of them will be used to determine your earnings. After you have made all 18 choices, we will put 18 numbered ping-pong balls into a cage. We will mix up these balls and then draw one ball from the cage. The number that appears on the ball that we draw will determine which choice will count.

For example, if we drew a ball with a 12 written on it, only your choice in Gamble 12 would count. None of your other choices would have any effect on your earnings. If you chose to purchase insurance in Gamble 12, you would pay the stated price of insurance in this decision. If you did 
not choose to purchase insurance in Gamble 12, the color of the ball drawn in this gamble would determine whether you lost any money in this experiment.

Even though only one of your 18 choices will count, you will not know in advance which gamble will be used to determine your earnings. Therefore, you should think about each of them carefully before submitting your choice.

Although each of you will make 18 choices, you may not face the same 18 gambles. Also, we have already shuffled your decision-sheets so each of you will receive your gambles in a different order. For example, one person may see Gamble 5 and then Gamble 3, while another person may see Gamble 7 first, and then Gamble 10. However, each of you will make decisions in 18 different gambles.

To summarize, this is what will happen during the rest of today's experiment:

1. We will show you 18 gambles; in each you must choose whether or not you wish to purchase insurance at the stated price. We will show you these gambles one at a time. After everyone has made their first choice, we will show you a second gamble, and so on for all 18 gambles.

2. After everyone has made all 18 choices, we will draw a numbered ping-pong ball to determine which ONE of these gambles will count. We will not look at your choices for any other gamble when determining your earnings.

3. We will come to each of you and see if you chose to purchase insurance in this gamble. If you purchased insurance, we will collect the stated price of insurance from you.

4. We will place into this bucket the number of orange and white ping-pong balls specified in the gamble.

5. We will mix up these ping-pong balls and then draw ONE ball from the bucket.

6. If we draw a white ball, no one will incur a loss. If we draw an orange ball, you will lose the amount specified in this gamble, unless you chose to purchase insurance.

7. You will sign a receipt form and then may leave the experiment.

We ask that you not talk to one another during this experiment. If you have any questions at any time, please raise your hand and one of us will come to you to answer the question. Before we begin do you have any questions about these procedures or how your earnings will be determined? 


\section{Descriptive Statistics for Demographic and Insurance Purchase Questionnaire}

Table 8: Experiment 2 demographics and insurance purchase experience.

\begin{tabular}{lccccc}
\hline Variable & Obs. & Mean & Std.Dev. & Min. & Max. \\
\hline Score on Quiz & 77 & 12.31 & 2.00 & 4 & 15 \\
Age & 77 & 21.42 & 2.98 & 18 & 36 \\
Gender is male & 77 & 0.52 & 0.50 & 0 & 1 \\
White & 77 & 0.16 & 0.37 & 0 & 1 \\
Black & 77 & 0.61 & 0.49 & 0 & 1 \\
Asian & 77 & 0.14 & 0.35 & 0 & 1 \\
Raised in U.S. & 76 & 0.88 & 0.33 & 0 & 1 \\
Bought Renters Insurance & 77 & 0.10 & 0.31 & 0 & 1 \\
Bought Homeowners Insurance & 77 & 0.01 & 0.11 & 0 & 1 \\
Bought Car Insurance & 77 & 0.51 & 0.50 & 0 & 1 \\
Bought Health Insurance & 77 & 0.34 & 0.48 & 0 & 1 \\
Bought Extended Warranty & 77 & 0.34 & 0.48 & 0 & 1 \\
\hline
\end{tabular}

Table 9: Experiment 3 demographics and insurance purchase experience.

\begin{tabular}{lccccc}
\hline Variable & Obs. & Mean & Std.Dev. & Min. & Max. \\
\hline Score on Quiz & 31 & 13.00 & 1.59 & 10 & 15 \\
Age & 31 & 23.48 & 6.65 & 18 & 48 \\
Gender is male & 31 & 0.48 & 0.51 & 0 & 1 \\
White & 31 & 0.16 & 0.37 & 0 & 1 \\
Black & 31 & 0.55 & 0.51 & 0 & 1 \\
Asian & 31 & 0.19 & 0.40 & 0 & 1 \\
Raised in U.S. & 31 & 0.81 & 0.40 & 0 & 1 \\
Bought Renters Insurance & 31 & 0.10 & 0.30 & 0 & 1 \\
Bought Homeowners Insurance & 31 & 0.13 & 0.34 & 0 & 1 \\
Bought Car Insurance & 31 & 0.61 & 0.50 & 0 & 1 \\
Bought Health Insurance & 31 & 0.35 & 0.49 & 0 & 1 \\
Bought Extended Warranty & 31 & 0.35 & 0.49 & 0 & 1 \\
\hline
\end{tabular}


Table 10: Experiment 2 random effects probit models of experiment insurance purchase with demographic and real insurance experience data.

\begin{tabular}{|c|c|c|}
\hline Coefficient & $\begin{array}{c}\text { with } \\
\text { demographics }\end{array}$ & $\begin{array}{c}\text { with real } \\
\text { insurance experience }\end{array}$ \\
\hline Prob(Loss) & $\begin{array}{l}-17.022 \\
(1.773)^{* *}\end{array}$ & $\begin{aligned}-14.342 \\
(1.611)^{* *}\end{aligned}$ \\
\hline Load & $\begin{array}{l}-0.32 \\
(0.049)^{* *}\end{array}$ & $\begin{array}{l}-0.283 \\
(0.046)^{* *}\end{array}$ \\
\hline EV(Loss) & $\begin{array}{l}1.89 \\
(0.389)^{* *}\end{array}$ & $\begin{array}{l}1.735 \\
(0.367)^{* *}\end{array}$ \\
\hline Hypothetical & $\begin{array}{l}-1.633 \\
(0.427)^{* *}\end{array}$ & $\begin{array}{l}-1.500 \\
(0.407)^{* *}\end{array}$ \\
\hline $\begin{array}{c}\text { Interaction: } \\
\text { Hyp } \times \text { Prob(Loss) }\end{array}$ & $\begin{array}{l}13.457 \\
(2.226)^{* *}\end{array}$ & $\begin{array}{l}10.818 \\
(2.097)^{* *}\end{array}$ \\
\hline $\begin{array}{l}\text { Interaction: } \\
\text { Hyp } \times \text { Load }\end{array}$ & $\begin{array}{c}0.031 \\
(0.065)\end{array}$ & $\begin{array}{c}-0.002 \\
(0.062)\end{array}$ \\
\hline $\begin{array}{c}\text { Interaction: } \\
\text { Hyp } \times \text { EV }(\text { Loss })\end{array}$ & $\begin{array}{l}-1.221 \\
(0.507)^{*}\end{array}$ & $\begin{array}{l}-1.075 \\
(0.490)^{*}\end{array}$ \\
\hline $\begin{array}{c}\text { Score of } \\
\text { Current Event Quiz }\end{array}$ & $\begin{array}{c}0.040 \\
(0.091)\end{array}$ & \\
\hline Age & $\begin{array}{c}0.123 \\
(0.063)^{*}\end{array}$ & \\
\hline Gender & $\begin{array}{c}-0.323 \\
(0.341)\end{array}$ & \\
\hline Caucasian & $\begin{array}{c}-0.365 \\
(0.468)\end{array}$ & \\
\hline Asian & $\begin{array}{c}-0.559 \\
(0.512)\end{array}$ & \\
\hline US Raised & $\begin{array}{c}-0.281 \\
(0.569)\end{array}$ & \\
\hline $\begin{array}{c}\text { Purchased } \\
\text { Car Insurance }\end{array}$ & & $\begin{array}{l}-.395 \\
(0.322)\end{array}$ \\
\hline $\begin{array}{c}\text { Purchased } \\
\text { Extended Warranty }\end{array}$ & & $\begin{array}{c}-0.110 \\
(0.346)\end{array}$ \\
\hline $\begin{array}{c}\text { Purchased } \\
\text { Health Insurance }\end{array}$ & & $\begin{array}{c}0.527 \\
(0.359)\end{array}$ \\
\hline $\begin{array}{l}\text { Purchased Renters or } \\
\text { Homeowners Insurance }\end{array}$ & & $\begin{array}{c}0.554 \\
(0.521)\end{array}$ \\
\hline Constant & $\begin{array}{c}-0.397 \\
(1.856)\end{array}$ & $\begin{array}{l}2.016 \\
(0.362)^{* *}\end{array}$ \\
\hline $\begin{array}{c}\text { Observations } \\
\text { Number of Subjects }\end{array}$ & $\begin{array}{c}1368 \\
76\end{array}$ & $\begin{array}{c}1386 \\
77\end{array}$ \\
\hline
\end{tabular}

* Statistical significance at the five percent level.

** Statistical significance at the one percent level. 
Table 11: Experiment 3 random effects probit models of experiment insurance purchase with demographic and real insurance experience data.

\begin{tabular}{|c|c|c|}
\hline Coefficient & $\begin{array}{c}\text { with } \\
\text { demographics }\end{array}$ & $\begin{array}{c}\text { with real } \\
\text { insurance experience }\end{array}$ \\
\hline Prob(Loss) & $\begin{array}{l}-17.577 \\
(1.449)^{* *}\end{array}$ & $\begin{array}{l}-15.659 \\
(1.350)^{* *}\end{array}$ \\
\hline Load & $\begin{array}{l}-0.311 \\
(0.047)^{* *}\end{array}$ & $\begin{array}{l}-0.280 \\
(0.044)^{* *}\end{array}$ \\
\hline EV(Loss) & $\begin{array}{l}2.046 \\
(0.317)^{* *}\end{array}$ & $\begin{array}{l}1.915 \\
(0.303)^{* *}\end{array}$ \\
\hline Hypothetical & $\begin{array}{l}-1.857 \\
(0.425)^{* *}\end{array}$ & $\begin{array}{l}-1.799 \\
(0.408)^{* *}\end{array}$ \\
\hline $\begin{array}{c}\text { Interaction: } \\
\text { Hyp } \times \text { Prob(Loss) }\end{array}$ & $\begin{array}{l}13.942 \\
(1.988)^{* *}\end{array}$ & $\begin{array}{l}12.056 \\
(1.915)^{* *}\end{array}$ \\
\hline $\begin{array}{l}\text { Interaction: } \\
\text { Hyp } \times \text { Load }\end{array}$ & $\begin{array}{c}0.017 \\
(0.064)\end{array}$ & $\begin{array}{c}-0.012 \\
(0.062)\end{array}$ \\
\hline $\begin{array}{c}\text { Interaction: } \\
\text { Hyp } \times \text { EV }(\text { Loss })\end{array}$ & $\begin{array}{l}-1.364 \\
(0.456)^{* *}\end{array}$ & $\begin{array}{l}-1.240 \\
(0.446)^{* *}\end{array}$ \\
\hline $\begin{array}{c}\text { Score of } \\
\text { Current Event Quiz }\end{array}$ & $\begin{array}{c}0.010 \\
(0.093)\end{array}$ & \\
\hline Age & $\begin{array}{l}0.103 \\
(0.045)^{*}\end{array}$ & \\
\hline Gender & $\begin{array}{c}-0.444 \\
(0.344)\end{array}$ & \\
\hline Caucasian & $\begin{array}{r}-0.635 \\
(0.459)\end{array}$ & \\
\hline Asian & $\begin{array}{c}-0.683 \\
(0.509)\end{array}$ & \\
\hline US Raised & $\begin{array}{c}0.061 \\
(0.537)\end{array}$ & \\
\hline $\begin{array}{c}\text { Purchased } \\
\text { Car Insurance }\end{array}$ & & $\begin{array}{c}-0.396 \\
(0.323)\end{array}$ \\
\hline $\begin{array}{c}\text { Purchased } \\
\text { Extended Warranty }\end{array}$ & & $\begin{array}{c}-0.199 \\
(0.338)\end{array}$ \\
\hline $\begin{array}{c}\text { Purchased } \\
\text { Health Insurance }\end{array}$ & & $\begin{array}{c}0.611 \\
(0.356)\end{array}$ \\
\hline $\begin{array}{l}\text { Purchased Renters or } \\
\text { Homeowners Insurance }\end{array}$ & & $\begin{array}{c}0.832 \\
(0.479)\end{array}$ \\
\hline Constant & $\begin{array}{c}0.482 \\
(1.595)\end{array}$ & $\begin{array}{l}2.29 \\
(0.346)^{* *}\end{array}$ \\
\hline Observations & 1926 & 1944 \\
\hline Number of Subjects & 107 & 108 \\
\hline
\end{tabular}

* Statistical significance at the five percent level.

** Statistical significance at the one percent level. 